\section{Manuel \\ Lázaro Pulido}

\section{Universidad}

Nacional de

Educación a

Distancia-UNED

Universidad

Bernardo

O'Higgins,

\section{Chile}

mlazarop@fsof.uned.es

Recibido: 20.11.17

Aceptado: 11.04.18

\title{
Raíces franciscanas de la teoría suareciana de la ley*
}

\section{Franciscan Roots of Suarecian Theory about law}

Resumen: En el presente artículo indagamos en las posibles fuentes franciscanas del concepto de ley de Francisco Suárez. Tras realizar una breve exposición sobre su posición sobre la ley natural y la ley positiva en la que se señalan, así como las características naturalistas de la misma, intentando no caer en una lectura reduccionista. Luego se deja libre espacio interpretativo acerca del papel de la voluntad humana y de la comunidad humana. La novedad y profundidad de su pensamiento y sus consecuencias permiten rastrear, al menos, tres aspectos que remiten al pensamiento franciscano: 1) El primero responde al papel de la inteligencia y la voluntad en la formación de la ley, aquí señalamos como referencia la teorización realizada por el franciscano Alfonso de Castro -más franciscano que escotista-, que mantiene, los ecos de la escuela no solo en lo referente a las facultades del entendimiento y voluntad, sino también en lo referente al carácter epistemológicamente limitante de lo particular. 2) El segundo tiene que ver con la obligatoriedad de la ley inscrita en el decálogo, donde Suárez rememora sus lecturas franciscanas, especialmente las del Doctor Sutil. 3) La tercera descansa en el papel de la teoría suarista de la ley sobre el origen de la potestad, retomando, de nuevo, la raíz que nace de Alfonso de Castro, quien no desdeñara a su maestro Francisco de Victoria, pero a quien no siguió de manera pastueña, como tampoco hará Suárez de las lecturas tomistas.

Palabras clave: Ley; Alfonso de Castro; Francisco Suárez.
Abstract: The present study aims to identify the possible Franciscan sources of Francisco Suarez's concept of law by presenting his position towards natural and positive law, as well as its naturalistic characteristics. His non-reductionist view of the law leaves space for a free interpretation about the role of man's will, both as an individual and as a community. Three key features of the Franciscan teachings can be identified in Suarez's nobility and depths of thought. The first one corresponds to the role of intelligence and will to establish the law. In this aspect, Francisco de Castro is used as reference, who shows depicts Franciscan characteristics in relation to the understanding and will faculties, and to the epistemologically limiting character of the particular. Suarez's reasoning also resembles the Franciscan teachings in his remarks about the obligatory nature of the law inscribed in the Decalogue, especially those related to the Subtle Doctor. Finally, the third feature rests upon the Suarecian law theory about the origin of the legal authority, which finds its roots in de Castro.

Keywords: Law; Alfonso de Castro; Francisco Suárez. 
En 1999 Francisco Puy Muñoz publicó el interesante artículo titulado "Los conceptos de derecho, justicia y ley en el De legibus de Francisco Suárez (1548-1617)" (Puy Muñoz, 1999, pp.175-196), en el que señala cómo Suárez comentó la Summa theologica de Tomás de Aquino, siguiendo el procedimiento académico y metodológico de su época y continuando la exigencia de los planes de estudio de los jesuitas que le obligaban a ello. Esta exigencia le hizo toparse con el concepto de ley y realizar una reflexión sobre el mismo. Con un cierto tono de reproche, el autor continúa escribiendo sobre la intención del jesuita:

Pero, con la (plausible) intención de mejorarlo, y quizá también con el (reprobable) prurito de alcanzar originalidad, lo cotejó con otras muchas definiciones, así del propio Tomás, como también de otros jurisprudentes anteriores y posteriores a él, recibidas de la tradición clásica, o debidas a otros famosos maestros universitarios coetáneos ${ }^{1}$ (Puy Muñoz, 1999, p. 183).

Es muy difícil realizar en un escrito objetivo un juicio de intenciones sobre un autor - sea el resultado la calificación de una acción como buena o reprobable-. Nosotros no nos atrevemos a tanto, pero toda vez que queremos señalar la posible influencia del pensamiento franciscano sobre el pensamiento jurídico de Suárez, señalamos alguna consideración, no sobre la intencionalidad del Doctor Eximio, sino sobre su metodología. En este sentido, podemos calificar la realización que como intelectual supone la adopción de una $u$ otra metodología - en este caso en relación al acercamiento de las fuentes y argumentos de autoridad - que realiza Suárez. Podríamos decir en este caso -y utilizando una metáfora más o menos afortunada tomada de la actividad médica - que en la actitud frente al diálogo con otros autores, Suárez se resiste a ser un forense - por otra parte, oficio necesario - que realiza un comentario histológico de un cadáver. Más bien nos encontramos ante un médico que desea realmente proporcionar un cuadro clínico de un ser vivo, de modo que su obra es una especie de sesión clínica en el que caben las diferentes opiniones a partir de las pruebas diagnósticas y las opiniones expertas, para poder realizar finalmente un diagnóstico fundamentado y creativo sobre una enfermedad determinada. El fin es salvar a un ser vivo - dar vida - y no documentar la historia de un cadáver. Y más allá de la metáfora, lo que nos parece más adecuado es entender que la intención de la obra De Legibus de Francisco Suárez es la de ofrecer un modelo de reflexión teológico-jurídica sobre la Ley. Esto supone la realización de una exposición, reflexión y análisis exhaustivo sobre la ley que tenga en cuenta el plano sincrónico y diacrónico. El Tractatus de legibus ac Deo legislatore (1612), en la novedad del tratamiento de la ley y en su profundidad, es una obra en la que se propone una exposición en y para su mundo contemporáneo dialogando, a su vez, con los autores y las tradiciones que le anteceden.

Afrontar una temática desde la profundidad de pensamiento impide la monocromía, y más bien exige la policromía, es decir, no se puede afrontar esta tarea obviando las fuentes que alimentan el pensamiento, menos aún si la empresa nace de una experiencia académica. Esto supone que, como hemos mencionado, en su consideración sobre la ley - como lo hará en todas sus obras - el Doctor Eximio sistematiza la doctrina de sus predecesores; pero en el caso de la literatura teológicojurídica lo hace, especialmente, a través de la escuela clásica española. En este sentido, al hablar de las raíces franciscanas de la teoría suareciana de la ley hemos de acudir a las raíces presentes en el teólogo-jurista Alfonso de Castro como el interlocutor más cercano en el tiempo y en el espacio a Suárez. Efectivamente, la obra del teólogo franciscano es considerada una obra maestra y de referencia sobre la ley por el teólogo granadino (Suárez, 1612, Tractatus de legibus, I, 12, 2), como buen maestro de su tiempo. La referencia de Alfonso de Castro no es una cita extraña. Al contrario, su presencia es común en Coimbra, donde Suárez está gestando su obra sobre la ley. Así, Francisco Dias, compañero en la Universidad de

\footnotetext{
${ }^{1}$ Suárez, F. (1612). Tractatus de legibus ac Deo legislatore, proem. (Ed. prínceps), Coimbra: Didacum Gomez de Loureyro. Tenemos en cuenta la versión española de 1967, introducida por L. Vela: Tratado de las leyes y de Dios legislador, S. I., (trad. J. R. Eguillor) vol. I, Madrid: Instituto de Estudios Políticos y la edición crítica bilingüe de la Colección Corpus Hispanorum de Pace: (1971-2012). De Legibus I-IV y Corpus Hispanorum de Pace. Segunda Serie: De Legibus V-VI, Madrid: C.S.I.C.
} 
Coimbra, decano de la Facultad y, sin duda, interlocutor cercano a la obra de Suárez, tiene entre otros a Alfonso de Castro como un autor de referencia a la hora de interpretar la norma jurídica ${ }^{2}$. Estas circunstancias señalan que es posiblemente de la mano de los conimbricenses que Suárez reconoce el pensamiento escotista.

\section{Teoría suareciana de la ley}

Ciertamente, Suárez está muy interesado en reflexionar sobre el derecho y la justicia, pero, sobre todo, desea pensar la ley como espacio de regulación de la vida humana. Para Suárez la ley en su modalidad de ley natural, si bien hace referencia a las cosas de la naturaleza, se aplica con propiedad cuando se aplica a los seres racionales con libre albedrío bajo la obligación de la voluntad de Dios (Suárez, 1612, Tractatus de legibus, I, 3, 8; II, 4, 6). Ciertamente, para Suárez, Dios, hombre y estado son realidades diferentes, aunque relacionadas jerárquicamente.

Si bien el único ser y realidad necesaria es Dios, la ley se hace presente de forma necesaria para el ser humano, una vez instituida la comunidad humana de hombres libres y racionales. Consecuentemente, la criatura racional por el mismo hecho de ser criatura tiene un superior a cuya providencia y autoridad está sometido (I, 3, 2). La ley natural además tiene un sentido práctico, pues los seres humanos dotados de libertad pueden desviarse hacia el mal como una opción tan plausible como para el bien. La ley se erige en un instrumento útil para orientar al hombre al bien que le es propio, en virtud de la ley divina (I, 2, 2-3). Esta utilidad justifica desde la tradición la versatilidad de la ley que se hace manifiesta cuando el Doctor Eximius presenta diversas nociones de la misma, hasta un total de nueve: lex, lex divina, lex aeterna, lex naturalis, lex positiva, consuetudo, privilegium, fuero y statutum.

Suárez reformula la ley natural de modo que se relaciona con la ley positiva. La ley natural prescribe los actos que son en sí en conformidad con lo justo y lo honesto.
La ley positiva explica el proceso mediante el cual los seres políticos instituyen valores ya que en este caso un acto es bueno o malo en razón de que esté prescrito o prohibido por una autoridad política. La ley natural tiene como origen la ley divina - entendiendo como la ley que dimana de Dios $(1,3,14)$ - y ella se identifica con la ley divina prescriptiva ya que es el instrumento fundamental de aplicación de la ley eterna, de modo que la ley natural es participación de la ley eterna. Suárez afirma que es la ley "que reside en la mente humana para discernir lo bueno de lo malo" (I, 3, 9). Esto supone que la ley natural se presenta a la conciencia humana en tanto que es algo objetivo. La luz natural de la razón y la ley revelada expresada en el decálogo son las mediaciones por las que se manifiesta la ley eterna al hombre. La prescripción de la ley eterna es interior en sí y depende de la mediación racional del hombre intrínseca (luz natural) o extrínseca (revelación). Se trata de una ley de obligatoriedad externa y orientadora para el hombre. Por su parte, la prescriptividad de la ley positiva emana del poder político. La ley natural tiene un origen antropológico que depende del descubrimiento racional y el entendimiento como potencia receptiva $^{3}$. La ley positiva, sin embargo, sin repudiar la racionalidad a la hora de recibir la orientación de la ley eterna, depende de la voluntad: "En efecto, aunque esta voluntad no pueda tener efecto en el súbdito si no se le manifiesta suficientemente, esta manifestación es como la aplicación de la causa que obliga, no la causa y la verdadera razón de la obligación" (I, 5, 24).

Esta explicación de la ley natural y ley positiva no coincide en una concepción del mundo helenista

\footnotetext{
2 "Diego de Covarrubias, Gamarra, Fortunio García de Ercilla o Arteaga y Alfonso de Castro son fuentes sustantivas de primer orden, con importancia similar a la de Santo Tomás, Soto y Molina, o a la de otros juristas de renombre mundial como Francisco Connan y los máximos juristas del Medievo" (Abril, 1971-1972, p. 172).

3 "La ley natural está en el hombre, porque no está en Dios, siendo temporal y creada, ni está fuera de los hombres, porque no está escrita en tablas, sino en el corazón: y no en la misma naturaleza del hombre inmediatamente, según mostramos, ni la voluntad, porque no depende de la voluntad del hombre, sino que la ata y como la fuerza: luego es necesario que esté en la razón” (Suárez, 1967, II, 5, 8).
} 
(estoicismo) donde coinciden ser y deber ser (valor), del mismo modo que en la diferenciación preceptiva de la ley natural y la ley positiva, la posición suareciana se aleja de la concepción tomista de la generalidad del precepto como determinante de la esencialidad de la ley en general. La ley natural remite, por lo tanto, a una exterioridad cosmológica y esencial (natural) y a una exterioridad divina y eterna (sobrenatural).

La ley natural prescribe objetivamente, de forma que remite a una verdad que el ser humano puede descubrir a través de su razón (natural) o mediante el conocimiento que pueda tener de la revelación (el decálogo). Pero la ley positiva tiene una obligatoriedad que emana de la voluntad de los seres humanos entre sí, de un acuerdo que supone un consentimiento de los hombres ante la ley, toda vez que responde a la voluntad de los hombres que viven y se relacionan entre sí de forma organizada. Esta organización descansa sobre la base de la naturaleza de las relaciones que los hombres establecen entre sí y sobre la legitimidad del poder político como forma de organización de los seres humanos.

La ley natural y la ley positiva tienen dinámicas diferentes, pero no están separadas, al contrario, se relacionan y podríamos decir que lo hacen mutuamente. La ley natural que toma su carácter prescriptivo de la ley divina que refleja la ley eterna es un referente continuo de la ley positiva. Podríamos decir que supone un marco de referencia para las decisiones tomadas desde la voluntad por parte de la comunidad de los hombres. Esto no anula el hecho de que la ley natural es inmutable e invariable presentándose a la naturaleza racional de la que mana necesariamente. Por lo que la delimitación es el resultado de la mudanza extrínseca de la ley natural en la medida en que la materia puede recibir un cambio. Efectivamente, Suárez afirma que existen

tres órdenes de preceptos naturales: unos son los preceptos universalísimos, cómo no se ha de hacer el mal y se ha de hacer el bien; otros son las conclusiones inmediatas y totalmente unidas intrínsecamente a tales principios, como los preceptos del Decálogo; en el tercer orden hay otros preceptos que están mucho más separados de los principios y aun de los mismos preceptos del Decálogo (II, 15, 2).

La ley en Suárez remite a un orden superior de carácter metafísico y ontológico determinado por la verdad descubierta por la razón y también a un orden humano de carácter antropológico y político orientado por el bien común y determinado por la voluntad. En este sentido, el bien procurado por las leyes han de remitirse al marco de referencia de la ley natural que tiene como expresión los mandamientos de la ley divina que reflejan la ley eterna, de modo que este bien es tenido como tal en la medida en que emana de Dios ${ }^{4}$, pero sabemos, a su vez, del bien refrendado prescriptivamente por Dios porque es en sí bien de modo intrínseco.

Esta consideración de la ley positiva presupone una reflexión sobre el establecimiento del Estado y la comunidad política. Suárez no es un estricto tomista, pero en su antropología socio-política sigue la doctrina aristotélico-tomística del animal social, es decir, defiende la tesis de que el hombre no puede alcanzar su perfección en cuanto imagen de Dios autárquicamente, sino que necesita vivir en la sociedad organizada bajo la forma de Estado, formada y fundamentada en la voluntad divina. De este modo el poder del Estado se corresponde con la necesidad de establecer una comunidad organizada ordenadamente. La autoridad en la organización estatal garantiza bajo el mandato común de la contingencia de las decisiones voluntarias de los miembros de la comunidad, que pueden decidir colaborar o no en la constitución y conservación de este orden, el cual por otra parte, es necesario en la comunidad organizada de los hombres. La autoridad como expresión del poder público la ejercen todos los miembros de la sociedad en aras de la consecución de un bien común y la sustantivación de este poder, de forma que garantice que se ejerce la autoridad reflejada de la voluntad divina.

\footnotetext{
4 "La ley natural, en cuanto está en nosotros, no solo juzga el mal, sino que también obliga a evitarlo y, por tanto, no solo representa la disconveniencia natural de tal acto u objeto con la naturaleza racional, sino que también es señal de la voluntad divina que lo prohíbe" (Suárez, 1967, II, 6, 8).
} 
El bien común pretendido supone el orden, la justicia, la igualdad ante la ley y de forma concomitante puede incluir la consecución de bienes terrenales para una existencia digna del hombre.

La forma de Estado viene determinada por la practicidad a la hora de conseguir el fin fundamental de la sociedad que es la consecución del bien común -y no el bien dinástico-, sea esta una monarquía, una república o una democracia directa que bien puede darse, por ejemplo, en estados pequeños donde se dan circunstancias particularmente favorables. Esto es reflejo de la convicción en Suárez de que el poder legislativo radica en el pueblo, independientemente de la forma de gobierno.

\section{Raíces franciscanas}

Francisco Suárez proporciona diversas perspectivas novedosas sobre la ley y sus consecuencias, según hemos visto. De ellas vamos a fijarnos en tres en las que puede verse las raíces franciscanas de sus soluciones debidas al diálogo que Suárez establece con esta tradición. La primera responde al papel de la inteligencia y la voluntad en la formación de la ley. De la consecución del equilibrio sobre el entendimiento y la voluntad en la constitución de la ley surge otra cuestión relativa a la obligatoriedad del decálogo. Por último, nos fijaremos en la ley positiva y el papel de la teoría suareciana de la ley sobre el origen de la potestad.

\section{1. Voluntad}

No es de extrañar que Francisco Suárez, a la hora de reflexionar sobre la ley en general presente una síntesis personal que le lleve a elaborar una definición propia de ley en la que estén presentes diversos elementos de otros autores como inspiradores de su propuesta. Dichos elementos se incorporan como fruto del diálogo con las diversas opiniones presentes en la tradición teológicojurídica y en los ambientes académicos de su tiempo. Esta novedad explica que hablando de ley en general (Suárez, 1967, libro 1, capítulo 12), Suárez presente una personal definición, breve y sustanciosa - como muestra la literatura vertida al respecto- y que formula de la siguiente manera: "La ley es un precepto común, justo, estable y suficientemente promulgado" $(I, 12,5)$.
El Doctor Eximio llega a esta definición después de presentar diversas formulaciones señalando los aspectos referidos a la ley natural bajo la fórmula de la recta razón (Cicerón, San Clemente Alejandrino), a la ley humana o civil (Aristóteles, Graciano, el Digesto), pero, sobre todo, después de la reflexión que realiza entre la definición que dan el dominico Tomás de Aquino y el franciscano Alfonso de Castro. Tomás de Aquino, señala Suárez, dice que "la ley es el dictamen de la razón práctica en el príncipe que gobierna una comunidad perfecta"; más tarde señala la definición: "Ley es la ordenación de la razón para el bien común promulgada por el que tiene el cuidado de la comunidad" (I, IV, 4). Por su parte, Alfonso de Castro afirma que "ley es la voluntad recta del que representa al pueblo promulgada de palabra o por escrito con intención de obligar a los súbditos a que se sometan a ella" (Rodríguez, 2013, p. 49)5. Una tercera vía presenta el maestro jesuita, la de Gabriel Biel, que define la ley como "una señal definitiva de la recta razón por la que esta dicta que uno queda obligado a hacer o no hacer algo" (I, IV, 4).

De las tres definiciones señaladas por Suárez, es la de Alfonso de Castro la que señala una distinción propia frente a la directriz racional, la "recta voluntad" que aparece en su obra De potestate legis poenale. Alfonso de Castro explica el concepto de ley en general - especialmente en cuanto ley humana- en su análisis

\footnotetext{
${ }^{5}$ En De potestate legis poenale Alfonso de Castro afirma: "Lex est recta voluntas ejus, qui vicem populi gerit, voce, aut scripto promulgata, cum intentione obligandi súbditos ad parendum illi" (I, 1, p. 12). Sobre el concepto de Ley en Alfonso de Castro, Rodríguez, M. (1959). El concepto de ley de Fray Alfonso de Castro, en Verdad y vida, 17, pp. 31-74.
} 
específico de la ley penal. Así se pregunta Quid sit lex El uso en la definición del término voluntad supone la afirmación de que la acción positiva (volición) y negativa (nolición) pueden ser incluidas como acción y omisión. Marcelino Rodríguez Molinero señala cómo Alfonso de Castro acepta sin vacilación la corriente voluntarista propia del escotismo y rechaza la línea tomista (Castro, De potestate legis poenale. I, 1). Suárez reconoce esta primacía en el De Legibus (Suárez, 1967, I, 5). La primacía de la voluntad queda bien clara en la definición de ley, como él mismo reconocerá. Piénsese, por ejemplo, en el legislador, en este caso el Príncipe, ¿cuál es el fundamento de la promulgación de la ley? Alfonso de Castro lo tiene muy claro: la voluntad. El entendimiento es subsidiario en la construcción de la ley. No se niega la intervención del entendimiento, sino su primacía: "el mismo nombre de ley, si atentamente se considera su etimología, dice terminantemente que es algo que se refiere a la voluntad y no exclusivamente al entendimiento" (De Castro, De potestate, I, 1). Esta primacía es signo de la libertad como elemento esencial de la conformidad humana, de su estructura más íntima y de las leyes que emanan de él, en cuanto naturaleza plenamente humana, distinta de las leyes de la naturaleza, que por ser naturales, son rígidas:

[L]a elección es acto que corresponde a la voluntad, no al entendimiento, puesto que la elección sin libertad no es facultad del entendimiento, ya que este actúa conforme a su naturaleza. De todo esto se deduce, que se equivocan los que afirman que la ley es un acto de razón (De Castro, De potestate, I, 1).

Cuando Suárez recuerda las posiciones de Cicerón y Clemente de Alejandría está realizando un ejercicio de rememoración de la tradición retomada por Tomás de Aquino en la que la ordenación de la razón es una norma directiva, una norma referencial, pero no una norma de carácter prescriptivo y, por lo tanto, no es una norma de obligatoriedad legal. La separación que realiza de las diferentes posiciones precedentes respecto a la "recta razón" y de la tendencia intelectualista quiere mostrar la influencia estoica de la ley en el Aquinate. Pero, como hemos señalado, la concepción de la ley en Suárez no está en el horizonte metafísico del estoicismo. Suárez parece mejor abonarse a la tesis franciscana donde la voluntad es el espacio del ejercicio de la libertad, y en el que el concurso del entendimiento queda delimitado a un carácter descriptivo, en cuanto que presenta a la voluntad el objeto de su decisión. Pero la presentación objetual no es la acción principal en el proceso de la ley, por lo que es la voluntad y no el entendimiento el que rinde carácter preceptivo a la ley. Alfonso de Castro muestra su franciscanismo al recordar que la doctrina tomista está, a su vez, haciendo presente, en este aspecto, al mismo Buenaventura que había suavizado las tesis naturalistas de Alejandro de Hales. Y esta suavización del naturalismo le lleva a la lectura de la misma desde el Sutil. En este sentido, cabe decir que la concepción de la ley, en Escoto, tiene que rendir cuentas a la libertad de la voluntad divina como fuente originaria y fundante del modo de principiar en los hombres y, por ende, de la estructura antropológica humana ("imperius est actus voluntatis").

Suárez no termina de decantarse abiertamente por la voluntad en el paradigma de la libertad al modo de la vía escotista. Efectivamente, la opción jesuita por la vía tomista, posiblemente motivada por una prevención frente al voluntarismo de la vía nominalista lleva a matizar el papel de la voluntad, cargando un valor prescriptivo mayor al entendimiento que el ofrecido por el escotismo, aunque sea un escotismo menos ortodoxo, como el que representa Alfonso de Castro. El escotismo ofrece un voluntarismo como espacio de la libertad en el que el entendimiento está presente de forma inherente, pero no actúa como contrapeso preventivo -como sugiere la presentación que realiza Suárez- de la voluntad. De este modo parece expresarse Suárez cuando afirma que la voluntad y el entendimiento desempeñan un papel fundamental en la ley, afirmando que el peso fundamental recae sutilmente en la facultad volitiva, sin que por ello se merme el protagonismo de ambas potencias en la

\footnotetext{
6 "Quoniam non de omni lege, sed de sola lege humana, quae poenam transgressori infligendam esse decernit, in hoc opere dissere statui: ideo necessarium esse censui, primum haec duo singulatim pertractare, quid sit lex humana, quid etiam poena, ut inde ómnibus aperte constare possit quid sit lex poenalis, de cujus solius potestate in praesentiarum disputare decrevi”. (De Castro, De potestate, I, 1).
} 
acción legislativa. Así, cuando en el capítulo tercero del libro segundo, Suárez reflexiona sobre la diferencia entre ley eterna e ideas divinas, el maestro jesuita señala que esta reside en que, mientras que las ideas, en el orden del entendimiento, son ejemplares de la acción divina, la ley eterna "imprime obligación a la obra", por lo que "esta distinta función es suficiente para establecer una distinción de razón” (De Legibus, II, 3, 10)․ Parece como si Suárez mirara la doctrina teológica de Tomás de Aquino - que está obligado a comentar de forma académica-, sin poder abstraerse de la óptica de la escuela franciscana, especialmente la escotista. Esta necesidad de "distracción" plantea problemas porque existen ciertos horizontes de la doctrina metafísicoontológica de la reflexión de la quidditas y la naturaleza divina que difícilmente pueden compatibilizarse, de forma que no puede satisfacer ni al tomismo ni al escotismo. De este modo, Suárez nos presenta una definición de la ley que podríamos calificar de aséptica, en la que intenta huir de elementos que le obliguen a tomar partido expreso sobre una tradición anterior. No mencionar al legislador evita tener que afirmar expresamente si este opera o no en relación a la razón o la voluntad. Esto supone, a mi entender, que el Doctor Eximio en un contexto tomista realiza una consideración positiva de la tradición franciscana, aunque intenta trascender las opiniones particulares, como él mismo indica.

La generalidad de la definición de ley de Suárez evita la confrontación. En ella no aparecen elementos presentes en las definiciones de ley de Tomás de Aquino y Alfonso de Castro. La ley queda reducida a un "precepto justo", desde el convencimiento de que la ley tiene vocación universal espacial (comunidad) y temporal (permanencia) y en la que el precepto se define por su particularidad espacial (individuos) y temporal (actos temporales concretos). Este último elemento nos muestra una tendencia hacia la imposibilidad de la generalidad a partir del particular que nos recuerda el pensamiento franciscano, especialmente el escotista en lo relativo a la imposibilidad de predicar lo universal a partir de lo particular en una perspectiva univocista.

\section{2. El decálogo: sobre la dispensabilidad de la ley}

Un segundo elemento en el que podemos ver la influencia del franciscanismo se manifiesta en la discusión sobre la dispensabilidad de la ley. En este caso no se trata tanto de una influencia directa, cuanto de un elemento que ayuda a pensar a Suárez. Y es que la disputa sobre la obligatoriedad de los preceptos del decálogo es una discusión en la que la presencia franciscana se hace patente. Cuatro tesis, presenta Suárez al respecto.

La primera tesis afirma la posibilidad por parte de Dios de dispensar de todos los preceptos naturales.

La segunda tesis afirma que Dios puede dispensar de los preceptos del decálogo denominados de la segunda tabla, pero no de los preceptos de la primera.

La tercera afirma que los preceptos negativos del decálogo no son dispensables, con excepción del quinto mandamiento que, juntamente con los afirmativos, sí pueden dispensarse.

La cuarta y última tesis, afirma que ninguno de los preceptos del decálogo es dispensable, ni siquiera por el poder absoluto de Dios.

Suárez se inscribe a la cuarta tesis sostenida por la tradición tomista. Santo Tomás había enseñado que la ley natural, como expresión de las ideas divinas y participación de la ley eterna, que no es otra cosa que la misma razón divina, es inmutable y necesaria, y consiguientemente que Dios no puede dispensar en los preceptos del Decálogo. No obstante, nos interesa señalar las dos primeras.

Respecto a la primera tesis sobre la posibilidad por parte de Dios de dispensar de todos los preceptos naturales, Suárez recuerda la vinculación ockhamiana de esta postura, que nace de la consideración del maestro franciscano de un derecho natural que refleja la teoría del principio teológico de la omnipotencia divina. En esta concepción, el orden dado por la ley natural puede ser

7 Ver: Baciero, F. T. (2007). La ley moral natural según Francisco Suárez, en Revista Española de Filosofía Medieval, 14, $108-109$. 
alterado por la voluntad divina de forma omnipotente, es decir, incluso de forma arbitraria. Suárez desecha esta posibilidad y argumenta afirmando que la doctrina de la omnipotencia divina no puede contradecir la cualificación de la naturaleza quiditativa de la cosa, o lo que es lo mismo, que no se puede realizar una lectura nominalista de la doctrina de la omnipotencia divina (Suárez, 1967, II, $15,3)$. En esta ocasión se ve con claridad la influencia del franciscanismo ockhamiano (nominalista) como lugar de límite especulativo.

En cuanto a la segunda tesis que afirma que Dios puede dispensar de los preceptos del decálogo denominados de la segunda tabla, pero no de los preceptos de la primera, Suárez recuerda su herencia escotista (Escoto, Briel, Almain) (Suárez, 1967, II, 15, 7). El maestro granadino de forma muy pedagógica describe esta segunda posición, especialmente en lo que refiere al sentido de la dispensa de la obligatoriedad de la ley natural, en cierta forma lo defiende cuando señala que:

hay que observar que Escoto no admite tanto la dispensa del derecho natural hablando por decirlo así formalmente, en sentido propio y riguroso, de los preceptos del derecho natural, sino que más bien saca fuera de ese derecho los preceptos de la segunda tabla y por lo concede que son dispensables. En consecuencia parece que no admite precepto alguno propiamente dicho de la ley natural fuera de los que se refieren a Dios. (Suárez, 1967, II, 15. 8).

En cuanto a la indispensabilidad o inmutabilidad de la ley natural, Escoto intenta responder a la constatación histórico-bíblica en la que aparecen episodios en los que parece que se dispensa algunas de las prescripciones de la ley divino-natural contenidas en la segunda tabla del decálogo, por ejemplo cuando los hebreos despojan a los egipcios de sus preciados bienes o cuando Jacob miente a Isaac para recibir la bendición paterna... hechos que parecen acontecer con el beneplácito de la voluntad divina.
Escoto enseña que la ley natural se refiere a la libre voluntad divina, y, por consiguiente, que Dios puede dispensar en algunos de los preceptos del decálogo, toda vez que no entrañan por sí mismos bondad o maldad moral, esencial y necesaria. En este sentido, el Doctor Sutil subraya la distinción entre las prescripciones - que siguiendo la terminología agustinista - se llaman de la primera tabla - los tres primeros - y los de la segunda tal - los siete restantes $-{ }^{8}$. Los primeros se refieren a Dios y los segundos, al prójimo. Lo que realmente hace que los preceptos sean de obligatoriedad natural es que estos descansan desde la omnipotencia divina, en la propia estructura real de los entes. En ningún caso Escoto afirma que se contradiga la naturaleza quiditativa de las cosas una vez establecidas. Lo que dice es que el mundo tiene una estructura que depende de la voluntad divina, pues podía haber sido constituida de otra forma teniendo en cuenta la omnipotencia absoluta de Dios. Los preceptos nacen de la libérrima condición del amor divino que es lo que realmente justifica la postura escotista. En este sentido, se entiende que la primera tabla responda, especialmente en su expresión negativa ("no..."), a la ley divina, y la segunda a la ley positiva ${ }^{9}$.

El pensamiento franciscano escotista establece una relación de diferencia - pero no de aislamiento - entre la ley positiva y la ley natural, en el sentido en que su diferenciación sirve para establecer los límites de la ley natural. Efectivamente, la ley positiva ayuda a poder juzgar y determinar la extensión prescriptiva de la obligatoriedad de la ley divina en tanto que ley natural que refleja la ley eterna. Es decir, la ley positiva nos ayuda a comprender cuáles obligaciones de la ley divina responden a la ley eterna y, por lo tanto, constituyen la prescripción de la ley natural. Lo que es lo mismo, nos muestra qué prescripciones del decálogo son leyes divinas y cuáles son obligaciones que reflejan, en realidad, circunstancias que no son ni universales, ni eternas. De un modo aún más claro, nos ayuda a pensar si el mandamiento de "Amarás a Dios sobre todas las cosas" tiene el mismo valor que el mandamiento de "No robarás". Esta diferenciación ayuda

\footnotetext{
8 Ver: Agustín de Hipona, Sermo 8, De decem plagis et decem praeceptis, (PL 38), pp. 69-72.

${ }^{9}$ Se puede ver: J. Duns Escoto, Opus oxionense, IV, d. 26, q. un., n. 9.
} 
a comprender la síntesis que Jesús realiza al sintetizar el decálogo en "Amarás a Dios sobre todas las cosas y al prójimo como a ti mismo".

En este apartado parece confirmase el hecho de que el argumentario jesuita se opone a la concepción ockhamiana -en la medida en que el nominalismo no asume la libertad nacida de la potencia sincrónica divina-, al tiempo que reverencia, con prudencia, el pensamiento escotista como se puede colegir de las palabras de Gaspar de Ribadeneira cuando señala cómo Suárez y Vázquez mantienen una posición de amor y reverencia a scoto $^{10}$. La apuesta referencial de Tomás de Aquino y el contrapeso del nominalismo de Ockham ejercen de limitadores a la lectura escotista de Francisco Suárez.

\section{3. El origen de la potestad}

La importancia matizada que Suárez proporciona a la voluntad en razón de la libertad de la potencia de Dios trasmitida al legislador, nos lleva a la cuestión sobre el origen de la potestad y la constitución del Estado. Luciano Pereña señala que "en sus primeras lecturas sobre la creación del hombre (1600), Francisco Suárez descubre la dinámica social en la constitución del Estado"11. El maestro granadino se pregunta "si los hombres, ateniéndonos exclusivamente a la naturaleza de las cosas pueden dar órdenes a los demás hombres y obligarles mediante auténticas leyes". Esta cuestión sobre el origen de la potestad legislativa tiene su razón de ser en la tesis de que "el hombre es libre por naturaleza y no está sometido a nadie más que a su Creador. Por consiguiente, el señorío de un hombre sobre otro va en contra del orden natural e implica tiranía"12. Suárez asienta su pensamiento en la libertad humana. Como hemos señalado en otros estudios (Lázaro, 2011), la importancia dada por Suárez al episodio de la libertad responde a diversas circunstancias tales como el objetivo ad extra, la teología protestante y ad intra, el conflicto de auxiliis, y encuentra en la antropología escotista y en su expresión jurídica en Alfonso de Castro un espacio de expresión combinando una equilibrada reflexión del pecado original frente a la antropología luterana basada en la teología del amor, que le lleva a una búsqueda de la sociabilidad (Pereña, 1975, p. XXIII). La teología protestante degrada la naturaleza humana afectando su existencia en la realización espacio-temporal de sus acciones. La respuesta frente a la naturaleza de la potestad no puede ser otra que la de la justificación del gobierno como delegación de la potestad divina. La función de la ley consiste en frenar y detener el pecado, más que en guiar a los hombres a la justicia divina. La teología luterana señala la corrupción ontológico-existencial del hombre y de su actividad. La cultura está corrompida y la cultura humana incluye toda obra humana y ello afecta a sus instituciones.

Frente al pesimismo antropológico luterano, la antropología escotista, leída jurídicamente por Alfonso de Castro y llevada a la época tridentina por él como teólogo, vislumbra en el horizonte teológico el hecho político-jurídico de que el hombre conserva de forma íntegra las posibilidades para darse sus propias leyes civiles. Para ello necesita que la autoridad legislativa $y$, en ella, las propias leyes se acuerden mediante el consenso de los ciudadanos. Este proceso provoca que el hombre tenga una autonomía libre para la formación de la ley. La autoridad civil no precisa de recaer en la autoridad religiosa. Lo que en el contexto escotista se dirimía en términos de la potestad política y de la Iglesia en la cuestión de los dos poderes, en Alfonso de Castro tiene una óptica centrada en las problemáticas de la Europa protestante, y en Suárez abre la perspectiva a la modernidad.

La liberación del hombre desde una perspectiva positiva de su constitución natural, provoca que la ley sea pensada desde parámetros diferentes a la racionalidad de la ley en su exigencia de control sociológico del pecado intrínseco. La voluntariedad como espacio de la ley

\footnotetext{
10 "Pater Suarez et Pater Vasquez pro amore et reverentia debitis Doctori subtilissimo ipsiusque praestantissimae scholae, tantum virum vindicarunt a calumniis immerito sibi impositis a Caietano et Banez". Gaspar de Ribadeneira, (1653). Tractatus de scientia Dei, Alcalá, p. 132.

${ }^{11}$ En su Estudio preliminar en F. Suárez, De legibus, III (1-16), vol. V, p. XXII.

12 "Hoc enim postea loquendo, possint imperare hominibus per proprias leges eos obligando. Ratio autem dubitandi esse potest, quia homo natura sua liber est et nulli subiectus nisi creatori tantum" (Suárez, 1612, De legibus, I, 5).
} 
permite liberar al hombre de una concepción tenebrosa y fatalista. La ley se concibe como un elemento público que manifiesta el autocontrol y autodominio del impulso moral humano y, por lo tanto, aparece teñido del color del principio de autonomía. Suárez puede - apoyado en el papel de la voluntad (escotista) en la ley-, afrontar la tensión dialéctica establecida entre heteronomía y autonomía, en una dinámica de la teología de la gracia nacida de la libertad de la omnipotencia divina. La posición de Alfonso de Castro y de Francisco Suárez se distancia del pesimismo luterano y del necesitarismo del entendimiento. El hombre libre tiene una capacidad de autocontrol y autonomía que nace de la contingencia de realización de su libertad operada en la voluntad. La bondad creadora de Dios manifestada en la voluntad humana legitima la ley y el control del pueblo, potestad que nace de la concepción de la ley como concreción de la voluntad humana de generar un autocontrol que ayude a ajustar el balance contingente de la voluntad humana que se pone en juego en su coordenada espacial (en el mundo social) y temporal (en la historicidad humana). Y es la conjunción de ambas coordenadas las que justifican el paso del fundamento moral a la concreción jurídica, del autodominio personal de la conducta humana a la elaboración de una soberanía efectiva y legítima que autorregule la conducta social, en fin la constitución de un "Estado de derecho".

No parece descabellado afirmar que desde el franciscanismo de Alfonso de Castro se perciba mejor el pensamiento de Suárez, sus ideas sobre la legitimidad de la potestad civil y su adelanto de las ideas democráticas frente al absolutismo monárquico del rey de Inglaterra Jacobo I. Suárez perfecciona la formulación de Alfonso de Castro, al que cita incluso con admiración, sobre el origen democrático clásico del poder, sobre la legitimidad de la ley en los términos referentes a que el pueblo es el sujeto inmediato del poder por derecho natural, a la transferencia del poder y el sujeto del mismo constituido, y en las formas de gobierno (Aníbal, 1958). Comentarios sobre Castro como los de J. Aníbal apuntan a esa inspiración en Suárez:
La doctrina de Castro ... incluye principios aplicables al régimen democrático constitucional... en el sentido de que este sistema democrático supone, como Castro, que el poder fundamentalmente reside en el pueblo, quien tratándose de Estados de mucha extensión territorial en que no puede ejercer convenientemente aquel poder inmediatamente por sí mismo, delega a sus representantes para que dicten la ley constitucional en que se determina una forma apta de gobierno según sus deseos, y las limitaciones que en el ejercicio del poder haya de observar el Jefe del Estado y sus colaboradores (Aníbal, 1958, p. 326).

Nos referimos a un Suárez cuyo mérito en estos asuntos reside en "haber vislumbrado la fuerza social del pueblo, como creador de vinculaciones prepolíticas y prejurídicas, partiendo del análisis de la tradición cristiana valorada en las circunstancias históricas de su siglo" (Elorduy y Pereña, 1965, p. XXII). Y sobre estas bases, la posición político doctrinal de Suárez triunfa como un modelo que trasciende los modelos populistas "fundándose en los principios eternos y absolutos de la sociabilidad humana" (Elorduy y Pereña, 1965, p. XXIX), a cuyo progreso social y humano debe servir el poder. De ahí que "Suárez defendía con la tradición medieval que la potestad política es otorgada por Dios directamente al pueblo, y por el pueblo a los gobernantes" ( $p . X X X)$. Es ahí donde se asienta la doctrina de la soberanía popular.

La línea de la interpretación tomista desde el espíritu de la riqueza de la tradición y el diálogo con la contemporaneidad de su época - a partir de una metafísica abierta a la ontología reflejada en Escoto y la lectura jurídica de Alfonso de Castro- propiciaron, sin duda, parte de la modernidad al pensamiento de Francisco Suárez, de modo que su pensamiento se presente al mundo del derecho como un hito a la hora de comprender la génesis y el desarrollo de la inteligencia jurídica moderna y contemporánea, como podría expresarse y decirse de su metafísica y su antropología. 


\section{Referencias}

Abril, V. (1971-1972). Génesis de la doctrina suareciana de la ley. Anuario de Filosofía del Derecho, 16, 163-187. Agustín de Hipona, Sermo 8, De decem plagis et decem praeceptis. En Opera Omnia, Patrología latina, vol 38. Aníbal, J. (1958). Las doctrinas democráticas en Fray Alfonso de Castro. Liceo Franciscano, 12, 343-350.

Baciero, F. T. (2007). La ley moral natural según Francisco Suárez. Revista Española de Filosofía Medieval, 14, 108109.

Castro, A. de. (1556). De potestate legis poenale. Lugduni: Sebastianum Barptolomaei.

Duns Escoto J. (1639), Opus oxionense. L. Wadding (Ed.). Lugduni.

Elorduy, E. y Pereña, L. (1965). Prólogo. En F. Suárez, Defensio fidei III. I. Principatus politicus o soberanía popular, E. Elorduy y L. Pereña, (Eds.), Madrid: C.S.I.C.

Lázaro, M. (2011). Posiciones antropológico-jurídicas en el Tratado De potestate legis poenalis de Alfonso de Castro. En J. Cruz (Ed.), Razón práctica y derecho. Cuestiones filosófico-jurídicas en el Siglo de Oro español (pp. 137-150). Pamplona: Eunsa.

Pereña, L. (1975). Estudio Preliminar, en F. Suárez, De legibus (III 1-16), CHP vol. XV, Madrid: CSIC.

Puy Muñoz, F. (1999), Los conceptos de derecho, justicia y ley en el "De legibus" de Francisco Suárez (1548- 1617). Persona y derecho, 40, 175-196.

Ribadeneira, G de. (1653). Tractatus de scientia Dei, Alcalá: Typographia Marie Fernandez.

Rodríguez, M. (1959). El concepto de ley de Fray Alfonso de Castro. Verdad y vida, 17, 31-74.

Rodríguez, M. (2013). Alfonso de Castro y su doctrina penal: El origen de la ciencia del derecho penal, Pamplona: Eunsa.

Suárez, F. (1612). Tractatus de legibus ac Deo legislatore, proem. (Ed. princeps), Coimbra: Didacum Gomez de Loureyro.

Suárez, F. (1967). Tratado de las leyes y de Dios legislador, S. I., (Trad. J. R. Eguillor). Vol. I, Madrid: Instituto de Estudios Políticos.

Suárez, F. (2012). De Legibus VI. (Ed. crítica bilingüe). En C. Baciero y J. M. García-Añoveros (Eds.), CHP, Segunda serie, vol 17, Madrid: CSIC. 